\title{
AN ERROR ANALYSIS OF ARGUMENTATIVE ESSAY (CASE STUDY AT UNIVERSITY MUHAMMADIYAH OF METRO)
}

\author{
Fenny Thresia \\ Teacher Training and Education Faculty, Muhammadiyah University of Metro, Metro Indonesia 34111
}

\begin{abstract}
The purpose of this study was study analyze the students' error in writing argumentative essay. The researcher focuses on errors of verb, concord and learner language. This study took 20 students as the subject of research from the third semester. The data took from observation and documentation. Based on the result of the data analysis there are some errors still found on the student's argumentative essay in English writing? The common errors which repeatedly appear are verb. The second is concord, and learner languages are the smallest error. From 20 samples that took, the frequency the errors of verb are 12 items $(60 \%)$, concord are 8 items $(40 \%)$, learner languages are 7 items (35\%). As a result, verb has the biggest number of common errors.
\end{abstract}

Keyword: error analysis, argumentative essay

\section{INTRODUCTION}

Writing is one of important aspects in language learning. Through writing, the students can share information and ideas in the written text. Writing performance can help them to think critically and to clarify their thoughts. They often discover what they really think and feel about people, ideas, issues, and events only in the actual process of writing. Writing is also as a learning tool, it can help them to conceive and to remember something. Even in some places, written language is more effective than spoken language because writing sometimes can be larger in gaining the audience than speaking products can be.

Writing can be very enjoyable as long as it have the ideas and the means to achieve it. But, writing is also not an easy activity, ideas or thoughts are not enough to constitute a good writing. Heaton states that writing is complex and difficult to teach and also to learn. Writing argumentative essay has become a complicated assignment for students. Moreover if the activity is done by the students of the third semester for making argumentative essay in English writing.
Hence, the students often make error in students' Argumentative essay.

The errors are the parts or process which cannot be separated of the language learning especially English as foreign language. It means that the students' errors are not failure of language learning process. Furthermore, the errors are sign that the students' really learn the foreign language, because when they make errors after that the teacher will give explanation more to correct the errors and it can also improve their knowledge. The students who don't have error in learning language automatically do not need to be treated and the teacher will never improve it. The teachers are aware that the students' errors as the process of learning in understanding the lesson and it needs to be analyzed carefully in order to increase the students' capability. The analysis of errors badly needed to explore and to get the conclusion in this research. It may be concluded that error analysis one of fields that included in language learning. Error is the process or parts which cannot be separated of the language learning especially in writing as the crucial subject for the students in writing argumentative essay. 
Argumentative essay is prepared to the students to make them think creatively. Although argumentative essay is necessary for the students but some common errors in students' argumentative essay writing are still found. Based on an observation done in the third semester in University Muhammadiyah of Metro shows that the students still doing errors. One of the reasons is that the students feel complicated to make a good argumentative essay exactly.

\section{ERROR ANALYSIS}

Gafes (2013:10) said that an error is a deviation from accuracy or correctness. According to Oxford Advance Learner's Dictionary (2009:445) error is a mistake, especially one that causes problems or affects the result of something. Based on the justification, it can conclude that an error is when a student produces an incorrect utterance or writing form because they have no enough knowledge to improve it correctly.

Making error is an unavoidable part of learning. The learners cannot learn language without first systematically doing errors. Thus, it is a natural thing if there are errors appear in the process of language learning. The errors should not seem as an indication of the students' failure. But in the contrary, they are the real proof that they are really learning. It is the deviations for the learners that are still developing knowledge of the language.

Brown (2000:20) states that learning to success, to understand, to read all involve a process in which success comes by profiting from mistake, by using mistake to obtained feedback from the environment and with that feedback to make new attempts that successively approximate goals. It means that the errors are badly needed to be analyzed.

\section{The Differences between Error and Mistake}

Brown (2007:217) states that it is very essential to distinguish between mistake and errors, technically both of them are two very divergence affairs. No one expects the students teaching theirs first language to produce only incorrect forms or a deviant. Moreover, Corder (1982:41) interprets sentences are erroneous therefore if they are unacceptable or inappropriate.

Ellis (1990:1) advises two ways to discern between errors and mistakes. The first one is to look into the consistency of learner's competence. If the pupils ever once in a while perform the correct form and sometimes the fault one, it is a mistake. But then, if he or she always performs it in never right form, it means an error. The second way is to ask learner to attempts to correct his own deviant utterance. Where learner cannot correct it, the deviations are errors; where he is successful, they are mistakes. Furthermore, James (2013: 2) has a nation that an error cannot be self-corrected, while mistake can be self-corrected if the deviation is pointed out to the speaker.

Based on the some justifications above, the researcher constructs that difference between mistake and error is: mistake is when the students do exercise or speak about something, then the students make a mistake and they are conscious about their mistake and they can correct and improve it to be right. While, error is a mistakes that students unable to correct their mistake when they perform their writing or speaking and cause of it the learners need explanation more from the teacher or lecturer.

\section{Classification of Error}

James cited in Brown (2007:217)

advises to discern the difference between global and local errors. Global errors need 
to be treated in some way since the message may otherwise remain garbled.

The classification of error, they are as follows:

a. Global errors affect the structure of the entire sentence, such as a missing essential part of the sentence - subject or verb. Krishna calls such errors "structural" and also rejects the possibility of their categorization. For example, the erroneous verb forms in the construction *the fine fat trout in the brook the santence doesn't have verb form, and wrong subject form. So, it can affect overall the structure of the sentence. The right sentence is the little bear saw the fine fat trout in the river.

b. Local errors are those which affect just part of a sentence or clause, such as errors in noun or verb phrases. Example: *He said that he was tired and that it going to bed. The sentence is wrong but it just affect the part of the sentence. The right sentence is He said that he was tired and that he was going to bed.

Regarding on the explanations above, it can conclude that the global error is fault involved in the overall structure of a sentence such as structure and verb form. Whereas, local errors are those which influence just part of a sentence or clause, such as errors in noun or verb phrases.

\section{Source of Error}

Richards in Schumann and Stenson (2013:1) in his article mention some source of error.

a. Interference errors: errors resulting from the use of elements from one language while speaking/writing another.

b. Intralingual errors: errors reflecting general characteristics of the rule learning such as faulty generalization, incomplete application of rules and failure to learn conditions under which rules apply.

c. Developmental errors: errors occurring when learners attempt to build up hypothesis about the target language on the basis of limited experiences.

\section{Writing}

Writing is the written productive language skill. It is a skill to convey information to a reader or a group of readers. It is realized by writer's ability to apply the rules of the language she or he is writing to transfer the information she or he has in her or his mind. Richard (2008:1) says that writing is at the very heart of Academic life. According to Grenville (2001:5) writing is when the writer starts with an attention -grabbing first sentence, then you move on to some really interesting stuff in the middle, and then you bring it all together at the end. Brown states writing is a manner that automatically make the writer thinks about something that never he or she thinking before. In conclusion, writing is more than just transforming our thinking or idea in written form because it also relays our heart meaning to the process of exploring any single word or feature that it have written and the process of applying our knowledge in our writing.

\section{ARGUMENTATIVE}

The argumentative is a genre of writing that requires the student to investigate a topic, collect, generate, and evaluate evidence, and establish a position on the topic in a concise manner.

Argumentative assignments generally call for extensive research of literature or previously published material. Argumentative assignments may also require empirical research where the student collects data through interviews, surveys, observations, or experiments. 
Detailed research allows the student to learn about the topic and to understand different points of view regarding the topic so that $\mathrm{s} /$ he may choose a position and support it with the evidence collected during research. Regardless of the amount or type of research involved, argumentative essays must establish a clear thesis and follow sound reasoning.

\section{The Structure of the Argumentative}

\section{Essay}

The structure of the argumentative essay is held together by the following:

1. A clear, concise, and defined thesis statement that occurs in the first essay of the essay.

2. Clear and logical transitions between the introduction, body, and conclusion.

3. Body essays that include evidential support.

4. Evidential support (whether factual, logical, statistical, or anecdotal).

5. A conclusion that does not simply restate the thesis, but readdresses it in light of the evidence provided.

\section{Organization}

All argumentative topics have PROs and CONs. Before starting writing, it is imperative to make a list of these ideas and choose the most suitable ones among them for supporting and refuting.

There are three possible organization patterns:

\section{Pattern 1:}

Thesis statement:

PRO idea 1

PRO idea 2

CON $(s)+$ Refutation(s)

Conclusion
Pattern 2:

Thesis statement:

CON $(s)+$ Refutation(s)

PRO idea 1

PRO idea 2

Conclusion

Pattern 3:

Thesis statement:

CON idea 1 -----> Refutation

CON idea 2 -----> Refutation

CON idea 3 -----> Refutation

Conclusion

A piece of writing is categorized as argumentative if it contains statements that serve the function of supporting other statement. It illustrates that argumentation consists of several statements to be obtained the point of view.

\section{An Error analysis in Writing Essay}

It is inevitable that all learners make mistakes and commit errors. However, that process can be hampered. Through realizing the errors and operating on them according to the feedbacks given. The researchers and language teachers realize that if the mistakes and errors of language learners in constructing the new language system are analyzed carefully, the process of language acquisition shall be understood, Matt (2002:2). Moreover, Oshima (2005:65) states that the practical aspect of error analysis is its function in helping to the improve action it must take to correct an unsatisfactory state of affairs for learner or teacher. It means that the 
students' argumentative need badly to be analyzed to find out the common errors.

In this argumentative essay writing. The students generally make common errors in writing argumentative essay such as using verb, concord, and learner language.

Hornby (2003: 1498) Verb is a word or group of words that expresses an action (such as eat), an event (such as happen), or a state (such as exist). A verb is one of parts of speech which is used to express an action or an existence. It is crucial to use the right verb form in a sentence because without a verb it can not be a good sentence.

Sargeant (2007:52) said that concord is peace and agreement. Concord is Subject-verb agreement, it meant that the subject and the verb match each other. Meaning to say, that concord is a concordance between a word and the other word in a sentence, either subject, predicate, object, or adverb. Concord in writing argumentative essay is subject and verb agreement. The errors of $\mathrm{S}-\mathrm{V}$ Agreement, is esensiil of one important aspects of errors made in the subjects who committed errors in this aspect of language, Azizi (2003:115).

Brown (2007:265) sums up that Learner languages as the second language learning is primarily, a process of acquiring whatever matters are different from the first language. In recent years the teachers have learn more and more to understand that second language learning is a process of the creative construction of a system in which learners are consciously testing about the target language from a number of possible sources of knowledge. Learners it relooked on not as producers of malformed, imperfect language replete with mistakes but as intelligent and creative beings proceeding through logical, systematic stages of acquisition, creatively acting upon their linguistic environment as they encountered forms and functions in meaningful contexts. Learners, in using English on their environment, construct what are they talking about based on legitimate system of language in its own right. Therefore, the students can be right and can make errors too.

English is really different from Indonesian. The learner language errors are mostly influenced by interference. Interference is the errors and difficulties that occur in our learning in using a foreign language, Wilkins (1978:80) .Learner languages of their mother tongue is one of the factors affecting their English language proficiency, and it is unavoidable. This is evident, especially in the early stages of learning English language.

\section{METHOD}

Case study is the type that the writer applied in this research. Because the writer wanted to explore the errors were commonly found on the students' argumentative essay in University Muhammadiyah of Metro. Cresswell (2002:15) define a case study is, in which the researcher explore in depth a program, and event, and activity, a process, one or more individuals. Through this research, the writer invited all readers to know deeply about a program, process and activity which are done on the students' argumentative essay.

This research was qualitative. Qualitative research has some characteristics. The first, qualitative research takes place in the natural setting. This means that the researcher can go to the place (home,office or campus) of the participant to conduct the inquiry. The second, qualitative research uses multiple methods that are interactive and humanistic. The qualitative researcher can adopt and apply various method in his or 
her study. The third, qualitative research is appear rather than tightly prefigured. It meant that the inquirer learns the best sites at which to learn about the central phenomenon of interest and the theory will emerge during a qualitative study. The fourth, Qualitative research is fundamentally interpretative. It meant that the inquirer can interpret the data and explore it. The researcher described the participant, interpreting the data, and then drawing the conclusion about the data intended.

\section{Data Source}

For gathering information, it was a must to discover important and accurate data from qualified source. Hence, the writer used purposive sample. Purposive sample is sampling technique of data source based on certain consideration. The writer choose the third semester of English department in University Muhammadiyah of Metro as the participants. As it was explained by Sutanto Leo et.al (2007:70) that there are basically two kinds of sources, namely primary sources and secondary sources was firsthand information. Then secondary sources provide second hand information. In this research, the primary source was the students' writing product (documentation).Then, the secondary source was observations.

\section{Data Collection Techniques}

The writer used the data as follows:

\section{Observation}

Creswell (2005:78) explained that observations, in which the researcher takes field notes on the behaviour or activities of individuals at the research site. The writer choose participant observation. The researcher observed the participants directly, then notes what the students do, say, and act. Sugiyono
(2011:227) the researcher used passive observation in this study. It meant that the inquirer was present of the scene of action but did not partipate.

\section{Documentation}

Documentation is a tool to collect some information in the form of written source or documenter from books, articles, English dictionary, encyclopedia, and documentation of students 'argumentative essay assignment to support the writer's reference.

\section{Data Analysis Technique}

The writer will apply Miles and Huberman Model to analyze her data. The components of this analysis model are pictured by this figure.

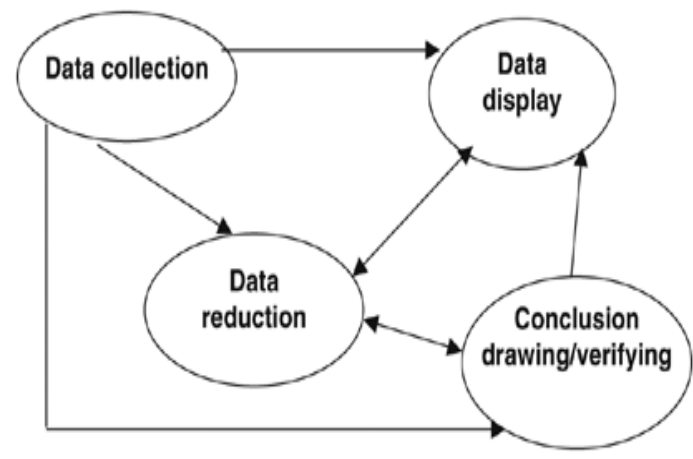

Figure II. Analysis Components of Miles and Huberman Model

Data analysis by Miles and Huberman model conducts the following steps:

1) Data collection is the step when the writer gathers all data which were used to complete the research.

2) The writer reduced the data she had gotten by summarizing and choosing specific things.

3) To display the data, the researcher usually used graphics, figures, or charts. The display should be able to describe the content entire the data.

Lastly, the researcher verified her research by making conclusion of data 
findings. In this research, the data were analyzed based on Miles and Huberman Model. According to Miles and Huberman, qualitative data is more likely to be described by words than numbers. It meant that, qualitative research more frequently utilized words to describe the result of analysis. Therefore, this research contained many words than numbers in explaining and analyzing the data. The words explained and depicted new perspectives. Regarding with the phenomenon above, the inquirer gave some examples of common errors on the students' argumentative essay below:

\section{The Errors in using Verbs}

Verb is one of the most important things that should be there in a sentence. Because to make a good sentence it must consist of subject, verb and object. The formula as follow: (Subject + verb + object + adverb)or (Subject + tobe (am, is, are) + object or complement). Focusing in this field, was to analyze the errors in using verb. The reseacher took 20 students' argumentative essay as sample to be analyzed about the errors in using verb. The result of this analysis was 12 students commit errors in using verb and 8 students made right form in using verb.

Based on the data, the errors which mostly happened on the students' argumentative essay were verb. Some writers repeatedly used incorrect verb when they wrote the verb after plural or singular subject

\section{The Errors in Concord}

Concord is peace and agreement. Concord is Subject-verb agreement, it meant that the subject and the verb match each other. Meaning to say, that the subject and the verb agree when they match each other. The inquirer took 20 students' argumentative essay as sample to be analyzed about the errors in using verb. The result of this analysis was 8 students commit errors in concord and 12 students made right form in using it.

\section{The Errors in Learner Languages}

English is obviously different from Indonesian. Some writers make errors called learner language because of their Indonesian influence. Corder (1982:78) summed up that to connote the idea that the learner's language is unique to a particular individual, that the rules of the learner's language are peculiar to the language of that individual alone.

\begin{tabular}{|c|c|}
\hline $\begin{array}{l}\text { The Students' } \\
\text { Code }\end{array}$ & $\begin{array}{c}\text { The Errors in Learner } \\
\text { Languages }\end{array}$ \\
\hline Student 1 & $\begin{array}{l}\text { Students elementary } \\
\text { school } * . . . \ldots . .\end{array}$ \\
\hline Student 2 & Support giving*.. \\
\hline Student 3 & Parents boy*...... \\
\hline Student 4 & His old brotherstep*..... \\
\hline Student 5 & Skin white*...... \\
\hline Student 6 & $\begin{array}{l}\text { There is found } \\
\text { something*.... }\end{array}$ \\
\hline Student 7 & World medicine*.......... \\
\hline
\end{tabular}

From the data above, 7 from 20 students that made errors in learner language. The learner language errors were mostly influenced by interference. Some writers interfered Indonesian into English. In Indonesian language, for example; adjective come after noun. On the contrary, in English, adjective precedes noun. Like skin white and Support giving. These example should be whiteskin and givingSupport. The result of students' erros in learner language was 35 $\%$. 


\section{DISCUSSION}

From the description of analysis above the writer found that the frequency of the students' common errors of using verb was $60 \%$ items, in concord was $40 \%$ items, and learner language was $35 \%$ items.

The result of this analysis describes that in fact there were some errors commonly found on the students' argumentative essay.

In conclusion, the writer furthermore found three common errors, namely verb has $60 \%$ error items, concord has $40 \%$, learner language has $35 \%$. Accordingly, the errors that repeatedly happen most was verb and the smallest errors was learner language. The errors which has been found are mostly caused by the students' interference from Indonesian language to English.

\section{Conclusion}

Based on the result of the data analysis, the writer eagerly would like to conclude this research as follows: There are some errors still found on the student's essay in writing class University Muhammadiyah of Metro. The common errors which repeatedly appear is verb. The second is concord, and learner languages is the smallest error. From 20 sample that took, the frequency the errors of verb are 12 items $(60 \%)$, concord are 8 items (40\%), learner languages are 7 items ( $35 \%$ ). As a result, verb has the biggest number of common errors.

\section{Suggestion}

Through this research, the writer would like to constructively give suggestions for:

1. The institution and the students

a. To follow up this research, the institution should organize programs to improve the students' understanding about English writing.

b. There is correction and reward for the students to write argumentative essay if the pupils it well done.

2. For the researcher The researcher should enhance her knowledge to support her research.

\section{References}

Brown,H. Douglas. (2000). Principle of language and Teaching, (Addison Wesley: Longman, 2000), Fourth Edition,

Crewell, W. J. (2005). Educational Research: Planning, Conducting, and Evaluating Quantitaive and Qualitative Research. Upper Saddle River, NJ: Pearson Merril Prentice Hall

Corder, S. P. (1982). Error Analysis and Interlanguage,London:Oxford University Press.

Gebhard, G. J. (2000). Teaching English as a foreign language or second language: a self-development and methodology guide. Ann Arbor, MI: The University of Michigan Press.

Graham, S. (2008). Effective writing instruction for all students.

Wisconsin Rapids: Renaissance Learning, Inc. (online). Available at http: //doc.renlearn.com /KMNet / R004250923GJCF33.pdf, accessed on February 25, 2011.

Honrby, AS. (2009). Oxford Advance Learner's Dictionary, New york: Oxford University Press.

Hutchinson, E. (2005). Argumentative Writing, America: Saddleback Educational Publishing, 
Hyland, K. (2009). Second language writing. NewYork, NY: Cambridge University Press.

Ibnian, S. S. (2011). Brainstorming and essay writing in EFL class. (online).Available at http://www.ojs.academypublisher. com/index.php/tpls/article/ download/.../269, accessed on 2 May, 2001.

Jun, Z. (2008). A comprehensive review of studies on second language writing. Papers in Applied Language Studies 12, 89-123. (online). Available at http://lc.hkbu.edu.hk/book/pdf/v12 05.pdf, accessed on February 9, 2011.

Onions, P. (2009). Thinking critically: An introduction. (online). Available at http://www.patrickonions.org/docs /academic/2009\%20Thinking\%20c ritically.pdf, accessed on February $22,2011$.

Oshima, A. \& Hogue, A. (2007). Introduction to academic writing. $3^{\text {rd }}$ ed. New York, NY: Pearson Education, Inc. 